\title{
Article \\ Binaural Background Noise Enhances Neuromagnetic Responses from Auditory Cortex
}

\author{
Dawei Shen ${ }^{1, *}$, Claude Alain ${ }^{1,2,3}$ and Bernhard Ross $1,3,4$ (D) \\ 1 Rotman Research Institute, Baycrest Centre for Geriatric Care, Toronto, ON M6A 2E1, Canada; \\ calain@research.baycrest.org (C.A.); bross@research.baycrest.org (B.R.) \\ 2 Department of Psychology, University of Toronto, Toronto, ON M5S 1A1, Canada \\ 3 Institute of Medical Sciences, University of Toronto, Toronto, ON M5S 1A1, Canada \\ 4 Department of Medical Biophysics, University of Toronto, Toronto, ON M5S 1A1, Canada \\ * Correspondence: dshen@research.baycrest.org
}

check for updates

Citation: Shen, D.; Alain, C.; Ross, B. Binaural Background Noise Enhances Neuromagnetic Responses from Auditory Cortex. Symmetry 2021, 13, 1748. https://doi.org/10.3390/ sym 13091748

Academic Editor: Francisco José Germain Martínez

Received: 9 July 2021

Accepted: 20 August 2021

Published: 19 September 2021

Publisher's Note: MDPI stays neutral with regard to jurisdictional claims in published maps and institutional affiliations.

Copyright: (c) 2021 by the authors. Licensee MDPI, Basel, Switzerland. This article is an open access article distributed under the terms and conditions of the Creative Commons Attribution (CC BY) license (https:// creativecommons.org/licenses/by/ $4.0 /)$.

\begin{abstract}
The presence of binaural low-level background noise has been shown to enhance the transient evoked N1 response at about $100 \mathrm{~ms}$ after sound onset. This increase in N1 amplitude is thought to reflect noise-mediated efferent feedback facilitation from the auditory cortex to lower auditory centers. To test this hypothesis, we recorded auditory-evoked fields using magnetoencephalography while participants were presented with binaural harmonic complex tones embedded in binaural or monaural background noise at signal-to-noise ratios of $25 \mathrm{~dB}$ (low noise) or $5 \mathrm{~dB}$ (higher noise). Half of the stimuli contained a gap in the middle of the sound. The source activities were measured in bilateral auditory cortices. The onset and gap N1 response increased with low binaural noise, but high binaural and low monaural noise did not affect the N1 amplitudes. P1 and P2 onset and gap responses were consistently attenuated by background noise, and noise level and binaural/monaural presentation showed distinct effects. Moreover, the evoked gamma synchronization was also reduced by background noise, and it showed a lateralized reduction for monaural noise. The effects of noise on the N1 amplitude follow a bell-shaped characteristic that could reflect an optimal representation of acoustic information for transient events embedded in noise.
\end{abstract}

Keywords: N1; P1; P2; gamma synchronization; efferent feedback; signal-to-noise ratio; gap detection

\section{Introduction}

Auditory perception is determined by the ratio between the stimulus and noise levels rather than the absolute stimulus intensity [1-3]. Background noise affects auditory perception dramatically and is commonly associated with reduced amplitudes and prolonged auditory-evoked responses [4-6]. However, researchers have shown that the hearing threshold decreased when adding an appropriate amount of noise to the target sound, although the improvement is small (1.4-1.7 dB) in normal-hearing participants [7].

Previous work about the effect of background noise on auditory-evoked responses focused on the N1 wave, the negative potential at about $100 \mathrm{~ms}$ after sound onset in the human electroencephalogram (EEG) and its equivalent in the magnetoencephalogram (MEG). N1 is elicited by an acoustic change in the auditory environment and may be functionally related to the readout of sensory registration and the update of an auditory memory before perception [8]. The N1 amplitude depends on the physical stimulus parameters, and background noise typically diminishes its amplitude [9]. However, a lowlevel background noise paradoxically yields an increase in the N1 amplitude when both the stimuli and noise were presented binaurally in MEG [10-12] and EEG studies [13-15]. In the study of Papesh, Billings and Baltzell [14], the noise-related increased in N1 amplitude recorded using EEG was more pronounced in binaural than monaural noise conditions.

Speech-in-noise intelligibility decreases when noise is presented at the same ear as the speech sound. However, some release from masking occurs when adding noise to the 
contralateral ear [16]. The activation of olivocochlear efferents [17] has been proposed as a neural mechanism underlying the release from ipsilateral masking. In addition to the olivocochlear efferent system, central auditory pathways may contribute to the masking asymmetry. Prior research revealed interactions between neural responses to a stimulus and contralateral noise along the central auditory pathway $[18,19]$. The present study aims to further clarify whether the noise-related enhancement reported in prior studies depends on the presence of binaural noise or whether monaural noise could also increase the transient evoked response by using MEG. Binaural auditory stimuli were presented while concurrent noise was either binaurally or monaurally presented. An N1 amplitude increase with binaural noise only would be in favor of the olivocochlear efferent hypothesis.

The present study also aimed to assess whether the observed N1 changes could be related to the impact of noise on earlier evoked responses. For instance, Alain, Quan, McDonald and Van Roon [11] revealed that the P1 amplitude, which appears in the EEG as a positive peak at about $50 \mathrm{~ms}$ after sound onset, decreased with increasing binaural noise. The P1 suppression could indicate preattentional sensory gating [20-22], which is essential in protecting the integrity of higher-order functions [23-26]. Here, we examine whether concurrent noise would show a sensory-gating-like modulation of the P1 and explore possible associations between $\mathrm{P} 1$ and N1 changes.

In addition to the sensation threshold, noise impacts perception. For example, gap detection thresholds, which measure auditory temporal acuity, are elevated in the presence of concurrent noise $[27,28]$. Cortical responses to stimulus gaps appear as P1-N1-P2 responses elicited by the trailing marker after the gap [29]. It remains unclear whether a low-level noise enhances the N1 gap response similar to the N1 onset response. Therefore, in the present study, stimuli with or without a gap were used to examine whether a noiseinduced increase in the $\mathrm{N} 1$ onset response would generalize to correlates of temporal processing.

The evoked responses are accompanied by event-related changes in the spectral power of the MEG or EEG. Possibly, an association exists between noise-induced modulation of sensory processing and event-related changes in gamma oscillation. For example, gamma activity was suppressed in sensory gating [30-32]. Thus, the examination of gamma activities may help understand how the manipulation of background noise affects the N1 amplitude. Additionally, the effects of background noise on N1 might extend to P2. Alain, Quan, McDonald and Van Roon [11] showed that the P2 amplitude decreases with more extensive binaural background noise. Ross, et al. [19] presented target sound and noise separately to each ear and revealed reduced P2 amplitude with contralateral masking. The present study examines how monaural and binaural noise affects the P2 amplitude to binaural stimuli.

To further characterize the mechanism of noise-induced increase in sensory-evoked responses, we examined how noise presentation (binaural or monaural), the level of noise intensity (high, low, or no), and the type of stimuli (with or without a gap) affected auditoryevoked P1-N1-P2 responses and event-related spectral modulations (gamma oscillations). We hypothesized that monaural noise would reduce contralateral P1 but would not affect ipsilateral P1 since the P1 reflects the early cortical registration of sound onset. However, binaural noise was expected to reduce the P1 in both hemispheres. Based on previous EEG [14] and MEG studies [10-12], only the low-level binaural noise should increase the $\mathrm{N} 1$ amplitude. The stimulus gap would not affect the onset $\mathrm{P} 1$ and $\mathrm{N} 1$ responses. However, the gap would affect the P2 since the P2 reflects a later pattern-recognition process [29]. Moreover, if the gamma activity is an early sensory response, the effects of noise type should be similar to those on the P1.

\section{Materials and Methods}

\subsection{Participants}

Eight men and seven women between 18 and 32 years of age (mean: 25.0 years; standard deviation, 3.7 years) participated in this study. They had normal hearing thresholds less or equal to 20 decibels (dB HL) at the octave frequencies between $250 \mathrm{~Hz}$ and $8000 \mathrm{~Hz}$ 
as measured by pure tone audiometry. Participants provided written consent after receiving information about the study. The study protocol was approved by the Research Ethics Board of Baycrest Centre and the University of Toronto.

We calculated the optimal sample size using $G^{*}$ Power (version 3.1.9.7), expecting effect sizes and data variance similar to a previous study using similar methods [11]. Provided the effect size $\mathrm{f}=0.25$ (partial $\eta^{2}=0.06$ ), we estimated the sample size $\mathrm{n}=14$ for type-I error rate $\alpha=0.05$ and power of the test $(1-\beta)=0.8$.

\subsection{Stimuli}

The stimuli were complex tones, composed of the first six harmonics of the fundamental frequency of $200 \mathrm{~Hz}$ at the sine phase and equal intensity. The stimuli of $95 \mathrm{~ms}$ duration included $5 \mathrm{~ms}$ linear onset and offset slopes to minimize spectral splatter. Half of the stimuli contained a $15 \mathrm{~ms}$ gap in the middle of the sound. The offset of the leading marker and onset of the trailing marker were smoothed with $5 \mathrm{~ms}$ linear slopes. We chose a $15 \mathrm{~ms}$ gap because such stimulus elicited a clear N1 gap response in a previous study [29]. The stimuli were synthesized using Adobe Audition 1.5 at the sampling rate of 44,100 Hz. Stimulus presentation was controlled by Presentation software (Version 13.0, Neurobehavioral Systems, Berkeley, CA, USA). The sounds were delivered via Etymotic ER3A insert earphones and reflectionless plastic tubes of length $2.5 \mathrm{~m}$. The stimuli were presented binaurally at an intensity of $80 \mathrm{~dB}$ sound pressure level (SPL). The intensities were calibrated using a Larson Davis System 824 SPL meter.

The higher intensity of the broadband Gaussian noise was $75 \mathrm{~dB}$ SPL, equivalent to the SNR of $5 \mathrm{~dB}$, which characterizes a challenging listening situation for speech-in-noise understanding. The low noise intensity of $55 \mathrm{~dB}$ SPL was equivalent to the SNR of $25 \mathrm{~dB}$. Thus, a normal-hearing individual would completely understand speech at this SNR despite the considerable noise. For convenience, we termed the two noise levels 'low' and 'higher' noise.

\subsection{Procedure}

Participants were presented with five experimental conditions: The binaural stimuli were presented without noise or with high or low binaural or monaural noise. The monaural noise was presented to the left ear. Binaural noise was identical in both ears. For each condition, a sequence of 300 stimuli was presented with an inter-stimulus interval uniformly randomized in $100 \mathrm{~ms}$ steps between $800 \mathrm{~ms}$ and $1200 \mathrm{~ms}$, lasting about five minutes. Within each sequence, 150 stimuli with a gap and 150 without were presented in random order. Presentation of noise started before the onset of the sequence and was held constant throughout stimulus presentation. Each experimental condition was presented twice. Thus, each participant was presented with ten sequences (i.e., block) of stimuli. The Latin-square design was used for balancing the condition order. The participants watched a subtitled muted movie of their own choice during the auditory presentation and were instructed to ignore the stimuli and background noise. No specific task was required for the participants.

\subsection{MEG Data Acquisition and Analysis}

The MEG was recorded in a magnetically shielded room using a helmet-shaped 151-channel whole cortex neuro-magnetometer (OMEGA, CTF MEG, Coquitlam, BC, Canada). Participants sat in an upright position with their heads touching the top of the MEG helmet and were asked to minimize movement during recordings. The head position within the MEG was recorded before and after each block using head-indicator coils attached to the nasion and left and right preauricular points. Head movement was identified by a mismatch between both localizations of the fiducials. A block of MEG recording was repeated if the difference for any fiducial and any direction exceeded $5 \mathrm{~mm}$. In nine participants, one block was repeated, in one participant, two blocks, and another participant three blocks. The MEG was lowpass filtered at $200 \mathrm{~Hz}$ and sampled at a rate of $625 \mathrm{~Hz}$. 
The Brainstorm toolbox [33] was used to analyze the MEG data. For each participant, the head shape was digitized using a 3-D digitizer (Polhemus Fastrak) before the MEG acquisition. A pseudo-individual anatomy was created by warping the MRI template into the head shape using the Colin 27 MRI template as the default anatomy. Artifact components accounting for eye blinks, eye movements, heartbeats, and muscle activity were identified with independent component analysis [34] and subtracted from the data. The MEG data were parsed into epochs, including $100 \mathrm{~ms}$ of prestimulus baseline and $500 \mathrm{~ms}$ of poststimulus activity. For each participant, sensor data were averaged separately in each of the five noise conditions.

Dynamical statistical parametric mapping (dSPM) [35] was used to estimate the sources underlying the MEG activity. The dSPM provides a statistical map of z-scores. It is a linear measure and can be expressed as imaging kernels. This measure has been recommended to estimate sources of an average response and normalize the participant average before a group analysis [33,36]. Two scouts (MNI coordinates, left: $-42,-30,8.8$; right: $49.4,-28,13.1$ ) were created to display source activities based on the strongest activities. Each scout included 20 vertices. P1, N1, P2 peak amplitudes and latencies were examined. The measurement intervals were 40-60 ms for P1, 80-150 ms for N1, and 150-250 ms for P2, respectively. To further examine the gap responses, we subtracted the responses in the no-gap condition from those in the gap condition. The latency intervals for the gap responses were $95-115 \mathrm{~ms}$ for P1, 135-175 ms for N1, and 180-280 ms for P2.

We used a Morlet wavelet for time-frequency transform, which was defined by three cycles of sine and cosine functions within the full-width half-maximum of the Gaussian envelope [37]. The increase and decrease in spectral power compared to a baseline interval were called event-related synchronization (ERS) and event-related desynchronization (ERD), respectively [38,39]. Gamma (35-45 Hz) ERS was defined as the mean activity during the $50 \mathrm{~ms}$ to $100 \mathrm{~ms}$ interval.

\subsection{Experimental Design and Statistical Analysis}

We used a two $\times$ five factorial design with hemisphere (left, right) and stimulus condition (five levels: high binaural noise, high monaural noise, low binaural noise, low monaural noise, no-noise) as within-subjects factors. We examined the effects of hemispheres and noise type on P1, N1, and P2 sound onset and gap responses in auditory cortex source activity and gamma oscillation. The effects of noise on the evoked responses were further analyzed by subtracting the responses in the no-noise condition from those recorded in the monaural and binaural noise conditions and three-way ANOVAs (noise intensity: higher or low, noise laterality: binaural and monaural, hemisphere: left and right) were conducted. The Greenhouse-Geisser method was used to correct for inhomogeneity of the variance, if applicable. However, the nominal degrees of freedom were reported for the F-tests. SPSS (IBM, version 26) was employed to analyze data.

\section{Results}

\subsection{Auditory-Evoked Responses}

The butterfly plot of all MEG sensor signals in Figure 1A provides an overview of the time course of the auditory-evoked responses elicited by the stimulus onset under the no-noise condition. The corresponding topographic map of the magnetic field at the time of the N1 maximum revealed the dipolar patterns above the left and right temporal lobes (Figure 1B; MNI coordinates, left: $-42,-30,8.8$; right: 49.4, $-28,13.1$ ). The left and right auditory cortex waveforms (Figure 2A) exhibited prominent P1, N1, and P2 waves with peak latencies of about $50 \mathrm{~ms}, 100 \mathrm{~ms}$, and $200 \mathrm{~ms}$ after sound onset.

The sound onset after the $15 \mathrm{~ms}$ gap in the stimulus elicited event-related fields, referred to as the gap response. The gap response showed a tri-phasic P1-N1-P2 response like the onset response, however, with smaller amplitudes (Figure 2B). The results of twoway ANOVAs on onset and gap P1-N1-P2 amplitudes and latencies are shown in Table 1, and the group means of peak amplitudes in Figure 3. 
A

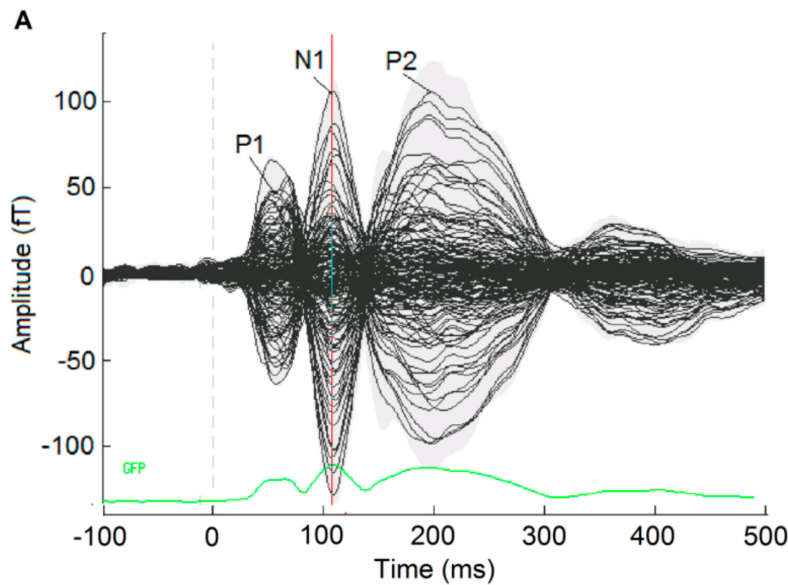

B

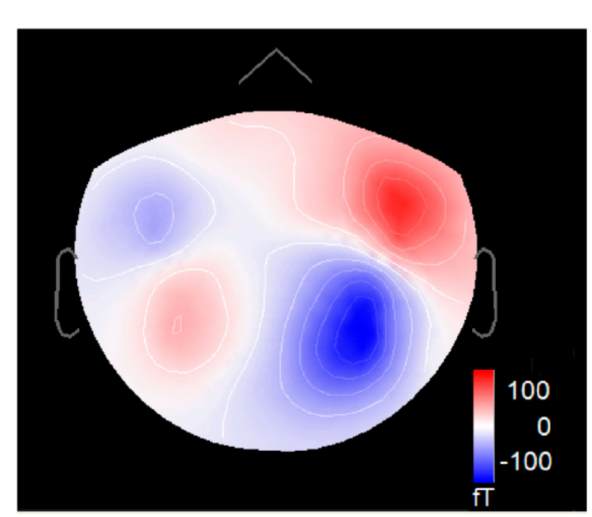

Figure 1. Auditory-evoked magnetic fields (AEF) in the no-noise condition, (A) butterfly plot of AEF time series from all MEG sensors, (B) 2-D magnetic field map at the N1 peak latency.

A

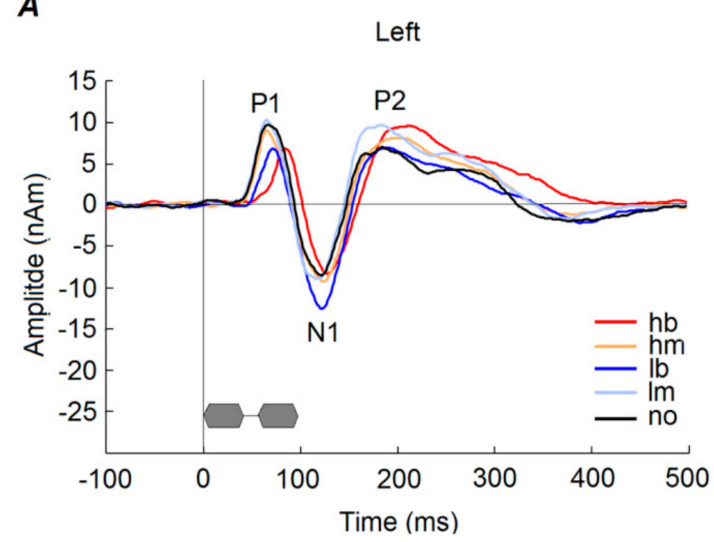

B

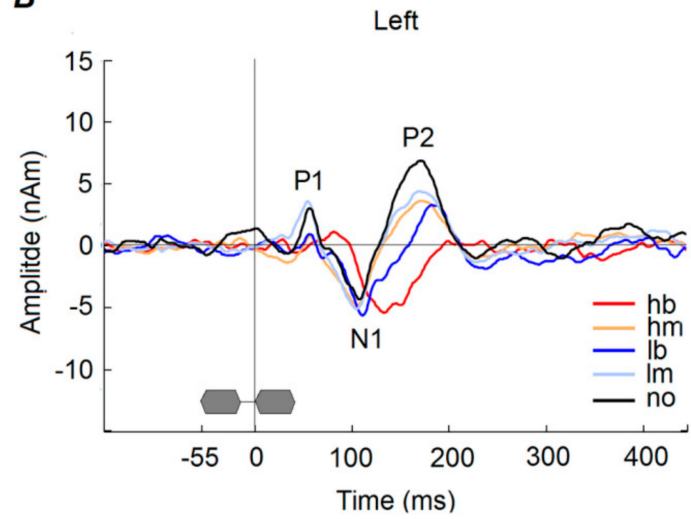

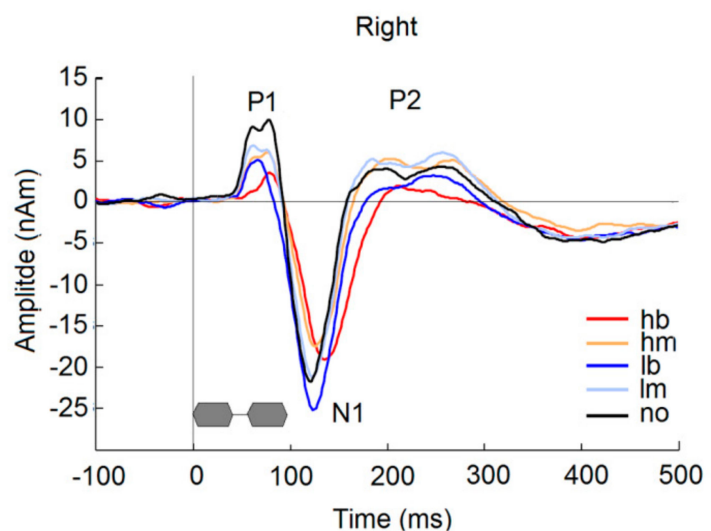

Right

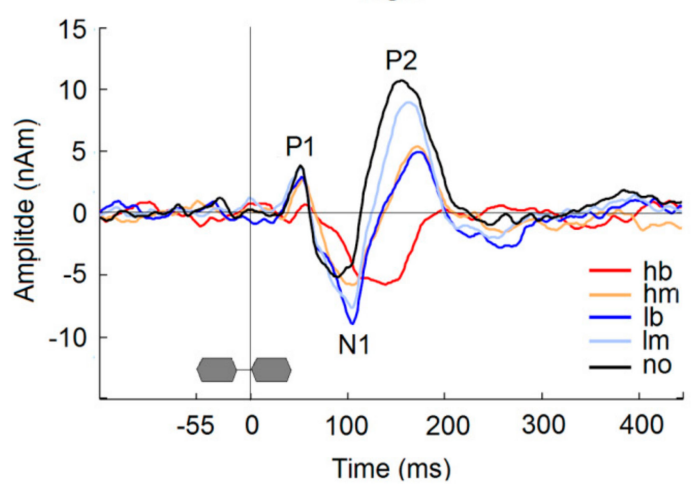

Figure 2. Source activities from bilateral superior temporal gyri for (A) onset responses (both stimuli with and without gap), (B) gap responses (difference between the gap and no-gap responses). hb: high binaural noise, hm: high monaural noise, lb: low binaural noise, lm: low monaural noise, no: no-noise. 
Table 1. Two-way ANOVA (hemisphere $\times$ noise type) for P1, N1, and P2 peak amplitudes and latencies.

\begin{tabular}{|c|c|c|c|c|c|c|c|c|c|c|}
\hline & & \multirow{2}{*}{ Source } & \multirow{2}{*}{ df } & \multirow{2}{*}{$\begin{array}{l}\text { Error } \\
\text { df }\end{array}$} & \multicolumn{3}{|c|}{ Amplitude } & \multicolumn{3}{|c|}{ Latency } \\
\hline & & & & & $F$ & $p$ & $\eta_{p}^{2}$ & $F$ & $p$ & $\eta_{p}^{2}$ \\
\hline \multirow{9}{*}{$\begin{array}{c}\text { Onset } \\
\text { Responses }\end{array}$} & \multirow{3}{*}{ P1 } & $\mathrm{H}$ & 1 & 14 & 1.624 & 0.223 & 0.104 & 6.037 & 0.028 & 0.301 \\
\hline & & $\mathrm{N}$ & 4 & 56 & 62.575 & $<0.001$ & 0.817 & 1.280 & 0.289 & 0.084 \\
\hline & & $\mathrm{H} \times \mathrm{N}$ & 4 & 56 & 3.269 & 0.018 & 0.189 & 2.117 & 0.091 & 0.131 \\
\hline & \multirow{3}{*}{ N1 } & $\mathrm{H}$ & 1 & 14 & 27.353 & $<0.001$ & 0.661 & 6.811 & 0.021 & 0.327 \\
\hline & & $\mathrm{N}$ & 4 & 56 & 5.481 & 0.001 & 0.281 & 13.272 & $<0.001$ & 0.487 \\
\hline & & $\mathrm{H} \times \mathrm{N}$ & 4 & 56 & 1.663 & 0.171 & 0.106 & 1.341 & 0.266 & 0.087 \\
\hline & \multirow{3}{*}{$\mathrm{P} 2$} & $\mathrm{H}$ & 1 & 14 & 4.050 & 0.064 & 0.224 & 6.171 & 0.026 & 0.306 \\
\hline & & $\mathrm{N}$ & 4 & 56 & 5.622 & 0.001 & 0.287 & 2.570 & 0.048 & 0.155 \\
\hline & & $\mathrm{H} \times \mathrm{N}$ & 4 & 56 & 6.237 & $<0.001$ & 0.308 & 0.884 & 0.479 & 0.059 \\
\hline \multirow{9}{*}{$\begin{array}{c}\text { Gap } \\
\text { Responses }\end{array}$} & \multirow{3}{*}{ P1 } & $\mathrm{H}$ & 1 & 14 & 4.920 & 0.044 & 0.260 & 10.010 & 0.007 & 0.417 \\
\hline & & $\mathrm{N}$ & 4 & 56 & 5.151 & 0.001 & 0.269 & 8.523 & $<0.001$ & 0.378 \\
\hline & & $\mathrm{H} \times \mathrm{N}$ & 4 & 56 & 1.246 & 0.302 & 0.082 & 1.261 & 0.296 & 0.083 \\
\hline & \multirow{3}{*}{ N1 } & $\mathrm{H}$ & 1 & 14 & 1.739 & 0.208 & 0.111 & 3.620 & 0.078 & 0.205 \\
\hline & & $\mathrm{N}$ & 4 & 56 & 4.116 & 0.005 & 0.227 & 20.250 & $<0.001$ & 0.592 \\
\hline & & $\mathrm{H} \times \mathrm{N}$ & 4 & 56 & 0.970 & 0.431 & 0.065 & 6.110 & $<0.001$ & 0.304 \\
\hline & \multirow{3}{*}{ P2 } & $\mathrm{H}$ & 1 & 14 & 7.287 & 0.017 & 0.342 & 1.699 & 0.213 & 0.108 \\
\hline & & $\mathrm{N}$ & 4 & 56 & 17.427 & $<0.001$ & 0.555 & 25.131 & $<0.001$ & 0.642 \\
\hline & & $\mathrm{H} \times \mathrm{N}$ & 4 & 56 & 2.438 & 0.058 & 0.148 & 0.696 & 0.598 & 0.047 \\
\hline
\end{tabular}

$\mathrm{H}=$ hemisphere; $\mathrm{N}=$ noise; $\mathrm{H} \times \mathrm{N}=$ hemisphere $\times$ noise type.

\subsubsection{P1 Onset Response}

Figure $4 \mathrm{~A}$ shows the group mean $\mathrm{P} 1$ amplitude after subtracting the brain responses elicited during the no-noise condition from those obtained in each noise condition. Negative values reflect noise-related amplitude attenuation, whereas positive values indicate noiserelated facilitation of the response amplitude.

The three-way ANOVA (noise intensity $\times$ noise laterality $\times$ hemisphere) revealed the main effects of noise intensity $\left(F(1,14)=79.750, p<0.001, \eta_{p}^{2}=0.851\right)$ and of noise laterality $\left(F(1,14)=71.218, p<0.001, \eta_{p}^{2}=0.836\right)$. The interactions between noise intensity and noise laterality $\left(F(1,14)=22.577, p<0.001, \eta_{p}^{2}=0.617\right)$ and between noise laterality and hemisphere $\left(F(1,14)=5.012, p=0.042, \eta_{p}^{2}=0.264\right)$ reached significance. Generally, P1 amplitude reduction was larger when the noise was presented binaurally than monaurally; and this reduction was more significant when the noise intensity was higher than low and more significant in the left than in the right hemisphere.

\subsubsection{N1 Onset Response}

The three-way ANOVA on the N1 amplitude (Figure 4B) revealed the main effects of noise intensity $\left(F(1,14)=11.852, p=0.004, \eta_{p}^{2}=0.458\right)$, and of noise laterality $\left(F(1,14)=6.146, p=0.027, \eta_{p}^{2}=0.305\right)$. Generally, $\mathrm{N} 1$ amplitude reduction was larger when the noise intensity was higher than it was low. N1 suppression was also more pronounced when the noise was presented monaurally than binaurally in low-intensity noise $(p=0.003)$ but not in higher-intensity noise $(p=0.804)$. Importantly, the N1 amplitude increased in the low binaural noise condition. 
A
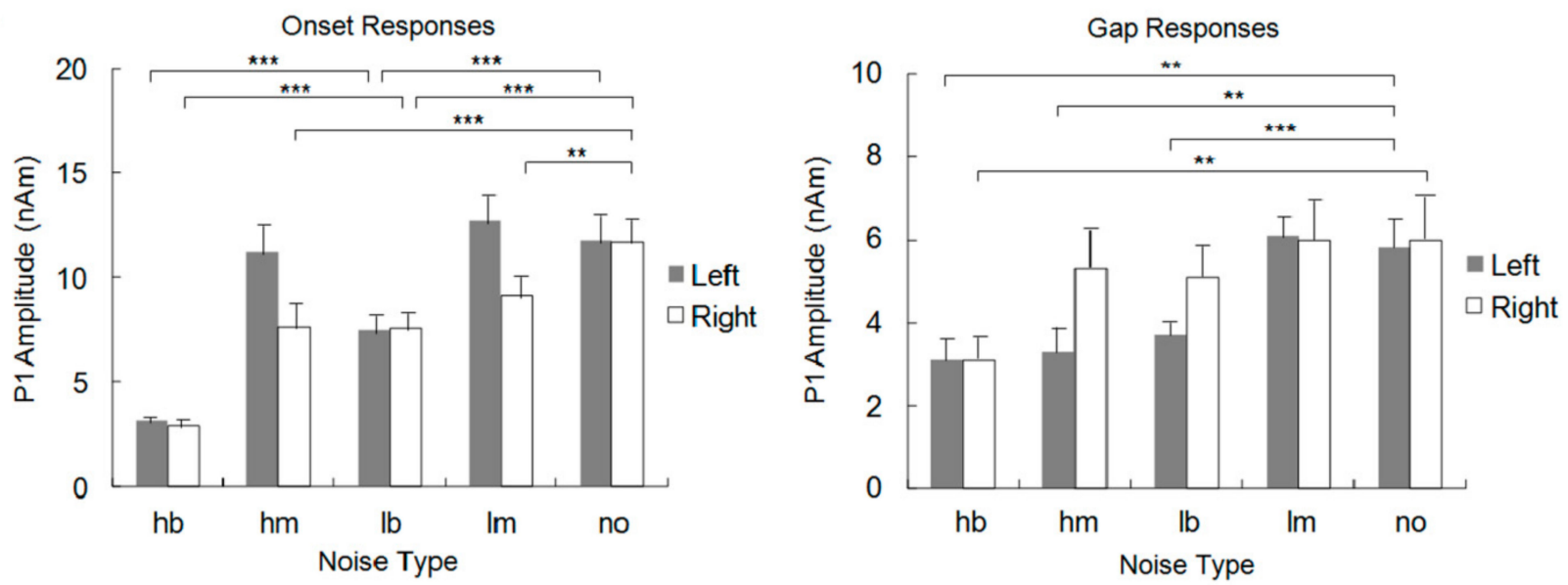

B
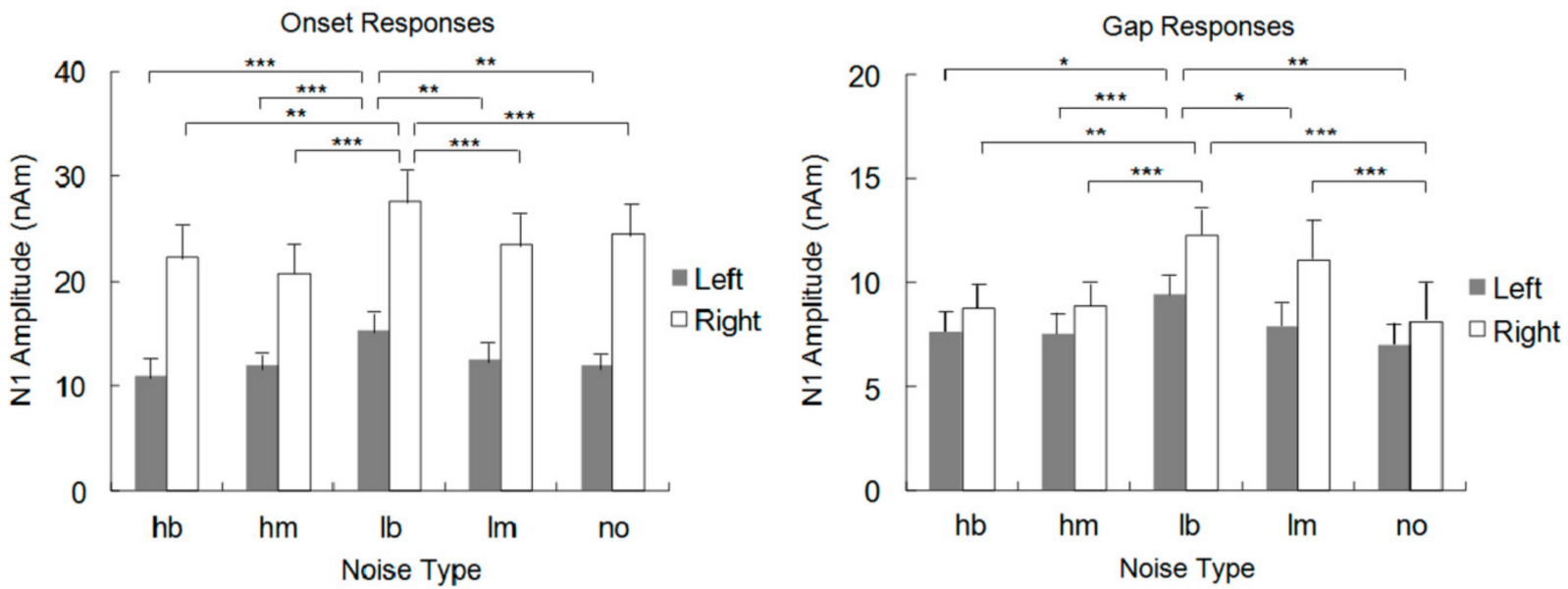

c
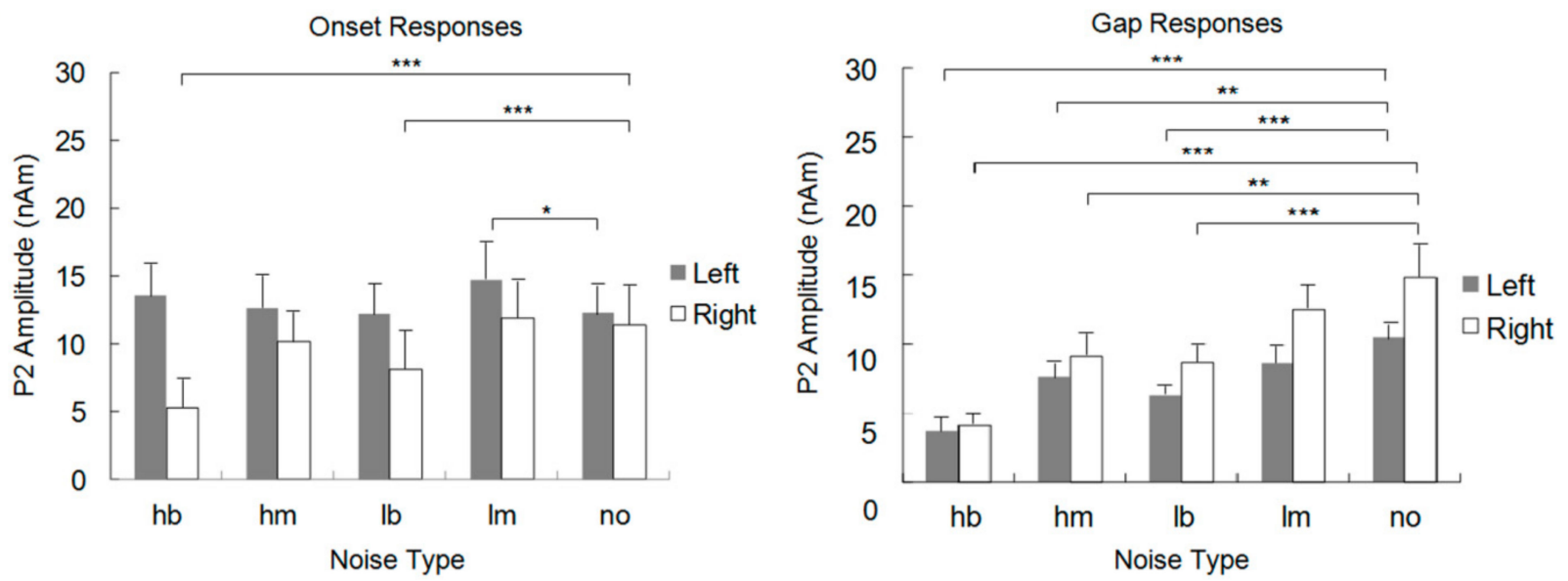

Figure 3. The effects of background noise on the mean values of (A) P1 amplitude, (B) N1 amplitude, and (C) P2 amplitude. ${ }^{*} p<0.10,{ }^{* *} p<0.05,{ }^{* * *} p<0.01$. Error bars represent +1 standard error. 
$\boldsymbol{A}$

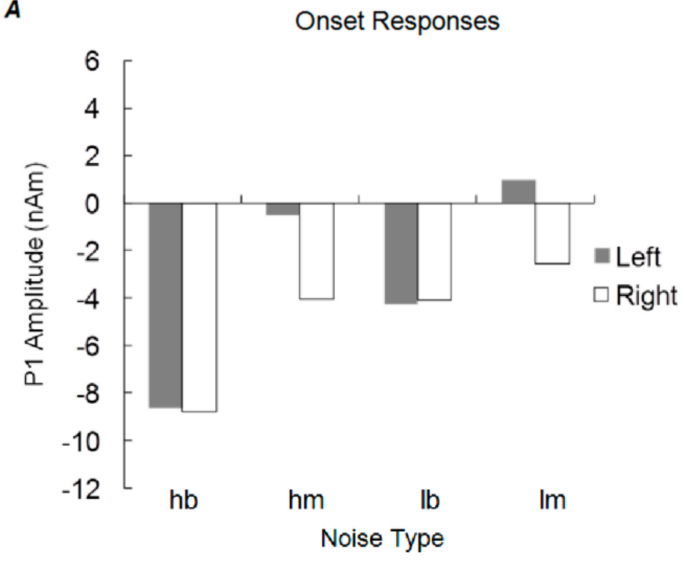

B

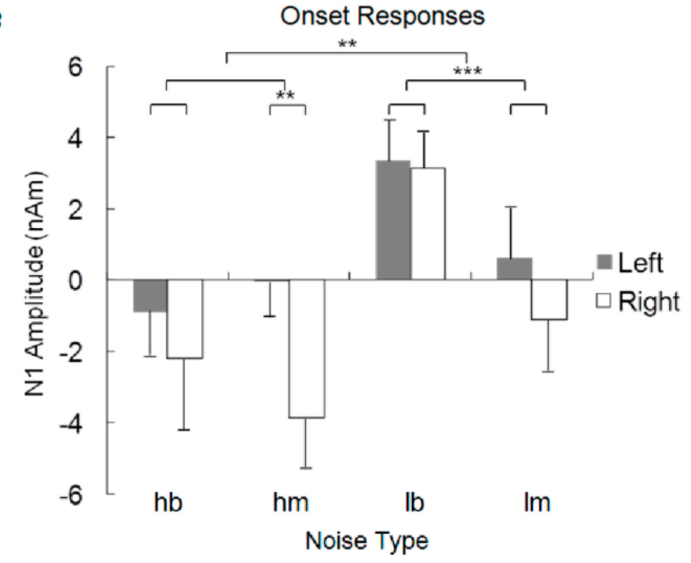

$c$

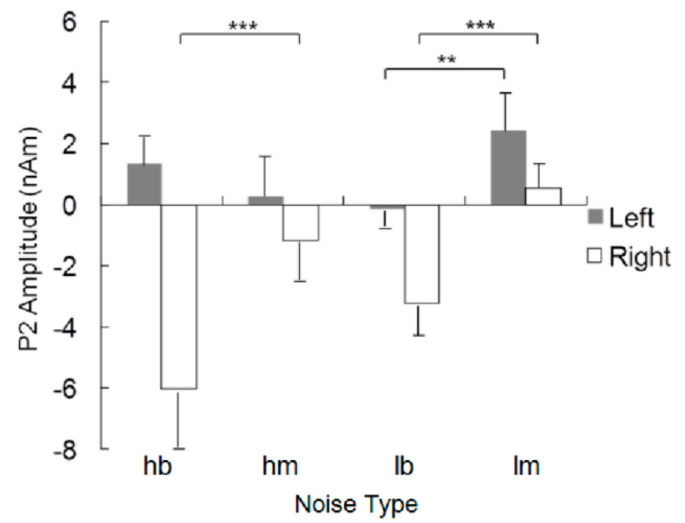

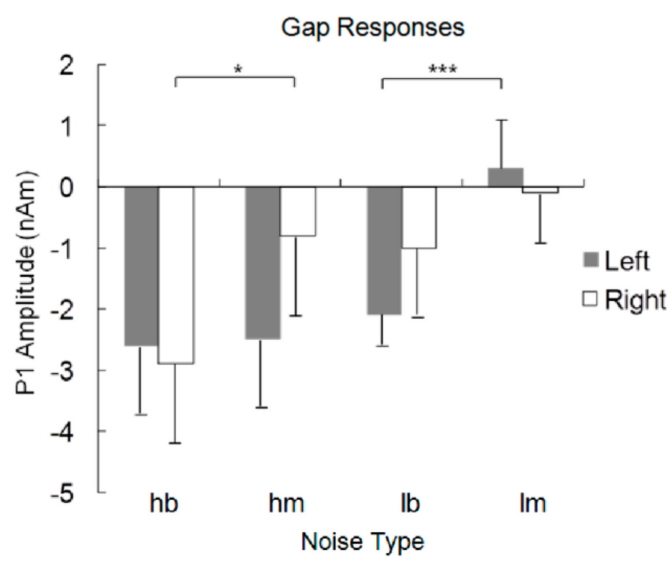

Gap Responses

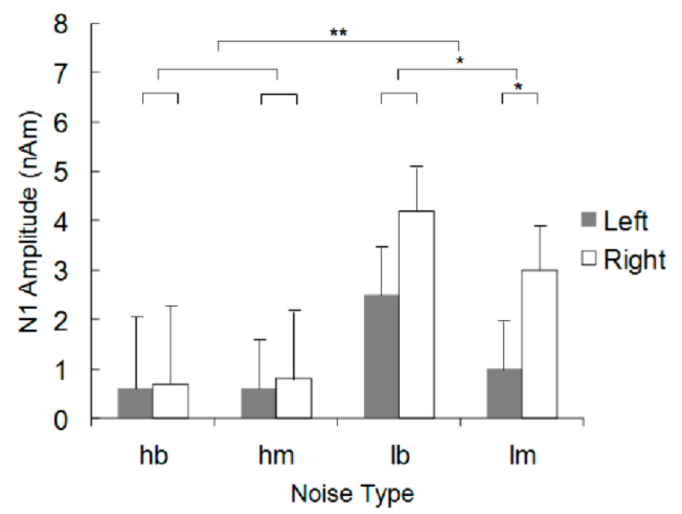

Gap Responses

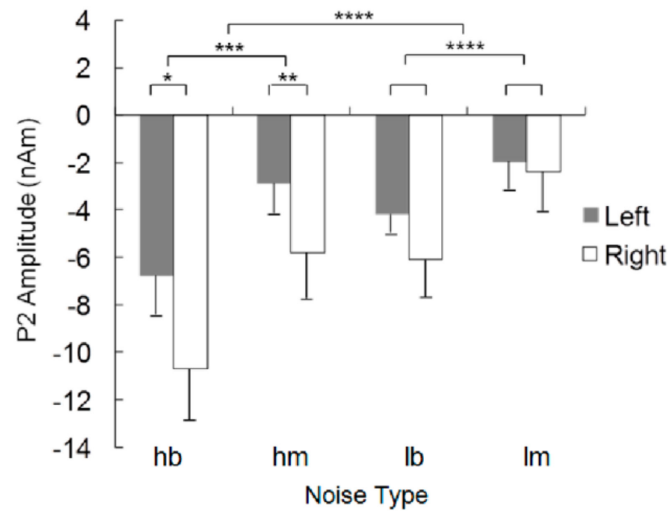

Figure 4. Group mean amplitude after subtracting brain responses elicited in the no-noise condition from those obtained in each noise condition. Negative values reflect amplitude attenuation, whereas positive values indicate noise-related enhancement in response amplitude. (A) P1 amplitude, (B) N1 amplitude, and (C) P2 amplitude. ${ }^{*} p<0.10,{ }^{* *} p<0.05,{ }^{* * *} p<0.01,{ }^{* * * *} p<0.001$. Error bars represent +1 standard error.

\subsubsection{P2 Onset Response}

The three-way ANOVA on P2 amplitudes (Figure 4C) revealed the main effects of noise laterality $\left(F(1,14)=10.863, p=0.005, \eta_{p}^{2}=0.437\right)$ and of hemisphere $(F(1,14)=5.094$, $\left.p=0.041, \eta_{p}^{2}=0.267\right)$, and a three-way interaction between noise intensity, noise laterality, and hemisphere $\left(F(1,14)=5.993, p=0.028, \eta_{p}^{2}=0.300\right)$. In the right hemisphere, the P2 amplitude reduction was larger when the noise was presented binaurally than monaurally $(p<0.001)$. In the left hemisphere, there was a two-way interaction between noise intensity 
and noise laterality $\left(F(1,14)=11.764, p=0.004, \eta_{p}^{2}=0.457\right)$. When the noise intensity was low, the P2 amplitude reduction was smaller when the noise was presented monaurally than binaurally $(p=0.039)$. However, when the noise intensity was higher, there was not such a difference $(p=0.274)$.

\subsubsection{P1 Gap Response}

The three-way ANOVA on P1 amplitudes (Figure 4A) revealed the main effects of noise intensity $\left(F(1,14)=6.443, p=0.024, \eta_{p}^{2}=0.315\right)$ and of noise laterality $(F(1,14)=10.009$, $\left.p=0.007, \eta_{p}^{2}=0.417\right)$. The three-way interaction between noise intensity, noise laterality, and hemisphere $\left(F(1,14)=11.744, p=0.004, \eta_{p}^{2}=0.456\right)$ reached significance. In the right hemisphere, the P1 amplitude reduction was slightly larger when the noise was presented binaurally than monaurally $(p=0.069)$. In the left hemisphere, there was an interaction between noise intensity and noise laterality $\left(F(1,14)=8.833, p=0.010, \eta_{p}^{2}=0.387\right)$. When the noise intensity was low, the P1 amplitude reduction was larger when the noise presented binaurally than monaurally $(p=0.001)$; however, when the noise intensity was higher, there was not such a difference $(p=0.858)$.

\subsubsection{N1 Gap Response}

The three-way ANOVA on N1 amplitudes (Figure 4B) revealed a main effect of noise intensity $\left(F(1,14)=6.222, p=0.026, \eta_{p}^{2}=0.308\right)$ and a marginal interaction between noise intensity and hemisphere $\left(F(1,14)=4.132, p=0.061, \eta_{p}^{2}=0.228\right)$. Interestingly, background noise did not reduce the N1 amplitude; instead, the N1 amplitude increased. Generally, the increase of N1 amplitude was larger when the noise intensity was low than higher; this increase was more significant in the right $(p=0.025)$ than in the left hemisphere $(p=0.081)$.

\subsubsection{P2 Gap Response}

The ANOVA on P2 amplitude (Figure $4 C$ ) revealed the main effects of noise intensity $\left(F(1,14)=23.285, p<0.001, \eta_{p}^{2}=0.625\right)$ and of noise laterality $(F(1,14)=27.609, p<0.001$, $\left.\eta_{p}^{2}=0.664\right)$, and a marginal effect of hemisphere $\left(F(1,14)=3.810, p=0.071, \eta_{p}^{2}=0.214\right)$. The interaction between noise intensity and hemisphere was significant $(F(1,14)=4.992$, $\left.p=0.042, \eta_{p}^{2}=0.263\right)$. Generally, the P2 amplitude reduction was larger when the noise was presented binaurally than monaurally, and marginally larger in the right than in the left hemisphere; it was also larger when the noise intensity was higher than it was low, and this difference was more significant in the right $(p=0.001)$ than in the left hemisphere $(p=0.008)$.

\subsection{Gamma (35-45 Hz) Synchronization}

Stimuli in the no-noise conditions elicited transient gamma-band responses [40] in both hemispheres. However, gamma responses were attenuated in the presence of noise (Figure 5). Bar graphs of the grand-mean gamma amplitudes are shown in Figure 6, and the results of the two-way ANOVA are in Table 2.

The three-way ANOVA (noise intensity $\times$ noise laterality $\times$ hemisphere) on the gamma responses revealed the main effects of hemisphere $\left(F(1,14)=5.819, p=0.030, \eta_{p}^{2}=0.294\right)$, and a marginal effect of noise laterality $\left(F(1,14)=3.145, p=0.098, \eta_{p}^{2}=0.183\right)$. The interaction between noise laterality and hemisphere reached significance $(F(1,14)=4.659, p=0.049$, $\left.\eta_{p}^{2}=0.250\right)$. Generally, the reduction of gamma responses was larger in the right than in the left hemisphere; it was also larger when the noise was presented binaurally than monaurally in the left $(p=0.049)$ but not in the right hemisphere $(p=0.956)$. 

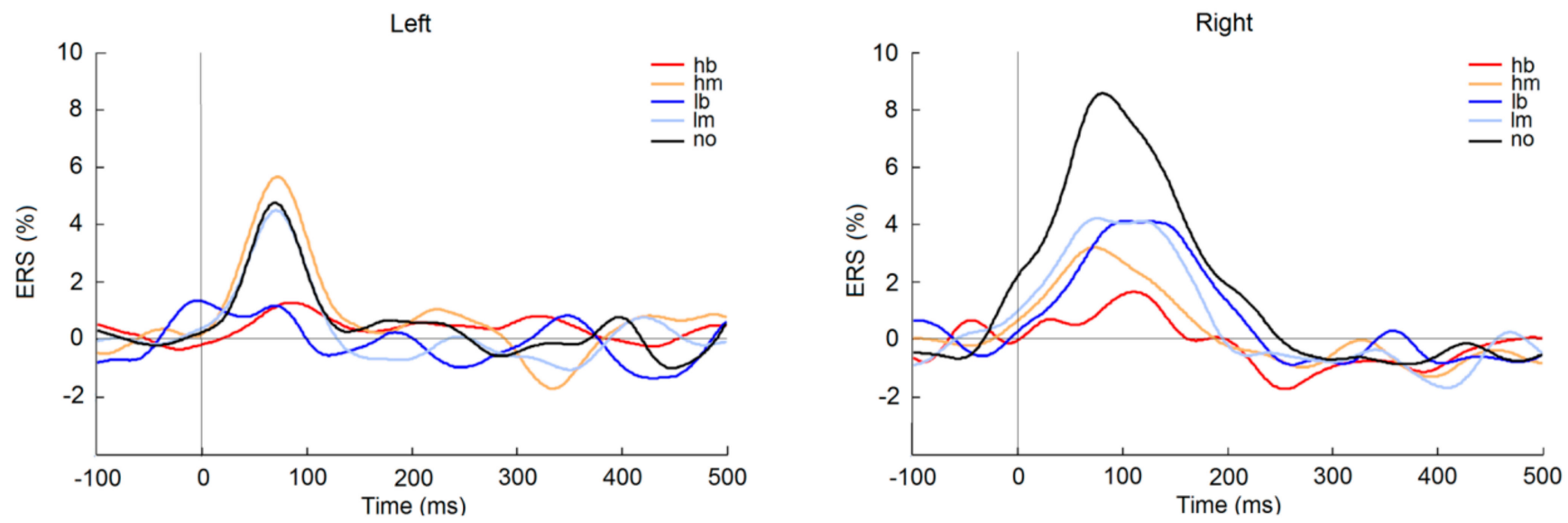

Figure 5. The effects of background noise on gamma synchronization after removing the evoked responses. hb: high binaural noise, hm: high monaural noise, lb: low binaural noise, lm: low monaural noise, no: no-noise.

Table 2. Summary of ANOVA (hemisphere $\times$ noise type) on gamma synchronization.

\begin{tabular}{cccccc}
\hline Source & $\mathbf{d f}$ & Error $\mathbf{d f}$ & $\boldsymbol{F}$ & $\boldsymbol{p}$ & $\boldsymbol{\eta}_{\boldsymbol{p}}^{2}$ \\
\hline $\mathrm{H}$ & 1 & 14 & 0.550 & 0.471 & 0.038 \\
\hline $\mathrm{N}$ & 4 & 56 & 3.765 & 0.009 & 0.212 \\
\hline $\mathrm{H} \times \mathrm{N}$ & 4 & 56 & 3.200 & 0.020 & 0.186 \\
\hline
\end{tabular}

$\mathrm{H}=$ hemisphere; $\mathrm{N}=$ noise type; $\mathrm{H} \times \mathrm{N}=$ hemisphere $\times$ noise type.

A

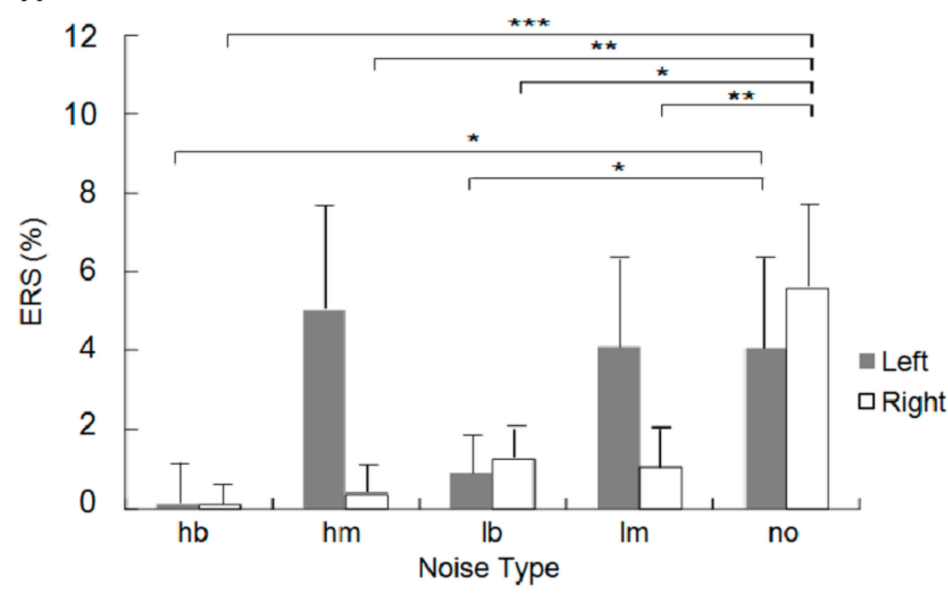

$B$

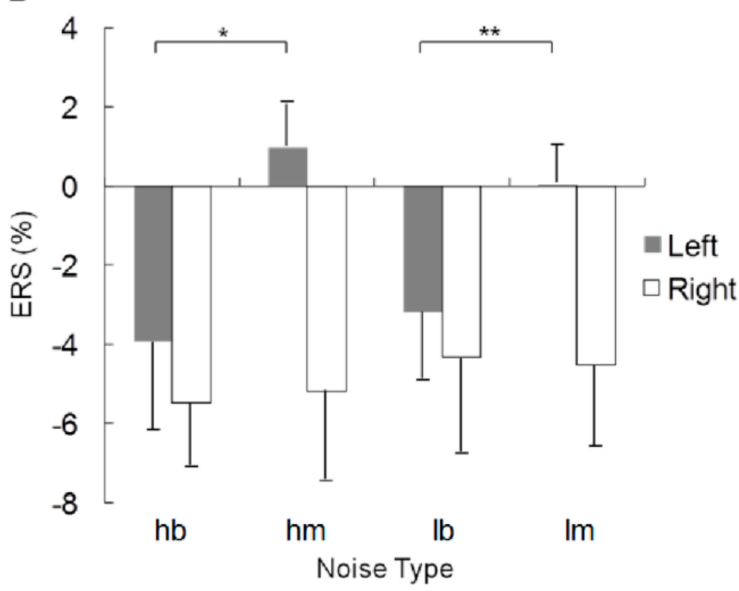

Figure 6. Group mean values of gamma synchronization (A) in the no-noise condition and the four noise conditions. (B) Group event-related synchronization (ERS) after subtracting brain responses elicited in the no-noise condition from those obtained in each noise condition. ${ }^{*} p<0.10,{ }^{* *} p<0.05,{ }^{* * *} p<0.01$. Error bars represent +1 standard error.

\section{Discussion}

The main findings of this study were that N1 amplitudes increased when stimuli were embedded in low-level binaural noise compared to stimuli presented in quiet conditions. The amplitude increases were observed for responses to the sound onset and gap responses. Monaural noise did not cause such amplitude increases. Moreover, increased response amplitudes in noise were specific to the N1 wave of the auditory-evoked responses. Background noise consistently attenuated P1 and P2 onset and gap responses, and the effects of the noise level and stimulation side showed distinct characteristics. The background noise also diminished the evoked gamma response, and the gamma power showed lateralized reduction for monaural noise. 


\subsection{Concurrent Noise Conditions}

The auditory stimuli were presented binaurally under all experimental conditions. In the no-noise condition, the auditory signals were projected from both ears along predominantly contralateral auditory pathways to bilateral auditory cortices. Monaural noise to the left ear interfered peripherally with the left ear stimulus, resulting in a masked neural signal toward the contralateral right auditory cortex. In contrast, binaural noise affected the afferent projection along the bilateral auditory pathways. In addition, we assume effects of central interferences between noise and stimulus representations.

\subsection{P1 Responses}

The effects of continuous noise on the onset P1 showed reduced amplitudes with increasing background noise consistently with those observed in prior EEG and MEG studies [10-12,14,41]. We analyzed the early volley of the P1 wave, which showed an effect of contralaterality. Monaural left ear noise, aiming to suppress afferent projection to the right auditory cortex, reduced the P1 right but not left. The lateralized reduction of the P1 was similar to the low and higher level of monaural noise. Binaural noise reduced the P1 amplitude symmetrically, which was more substantial with a high noise level than low-level noise. The gap P1 was attenuated and delayed with binaural noise. However, a lateralized reduction as observed for the onset responses was not evident.

The interpretation of the functional significance of the P1 amplitude is challenging because multiple excitatory and inhibitory neural generators contribute to the extracranial signal [42]. The main P1 cortical sources are localized in or near the primary auditory cortex in the superior temporal gyrus [43-45]. The P1 is associated with the initial registration of the physical characteristics of a sound. For instance, the P1 is sensitive to tone frequency [46] and intensity [41,47]. However, the investigations on the P1 amplitude also indicate sensory gating modulated by the prefrontal cortex $[44,48]$. Similar to a paired stimulus paradigm [22,49], we interpret different P1 amplitudes elicited by the same stimulus as an indication of a sensory-gating-like modulation.

\subsection{Evoked Gamma-Band Responses}

Pantev, Makeig, Hoke, Galambos, Hampson, and Gallen [40] observed an eventrelated $40 \mathrm{~Hz}$ magnetic gamma-band response that originated in the superior temporal gyrus in the 20-130 ms interval after stimulus onset and suggested involvement in essential perceptual processing. The evoked gamma activity is thought to reflect the match of sensory information with memory contents [50] and feature binding [51-55]. Monaural noise to the left ear attenuated the right hemispheric gamma response but did not affect the evoked gamma activity in the left hemisphere. The gamma activity was almost absent in both binaural noise conditions. Thus, the contralateral dominance of the effect of noise was even more strongly expressed for the gamma-band response than the P1 response.

P1 and gamma-band responses appeared in overlapping time intervals. In previous studies, both types of response showed suppression in a paired stimulus paradigm, and therefore, both have been associated with sensory gating [30-32]. However, P1 and gamma activity exist in parallel and show different functional dependencies with age, hearing loss, and speech-in-noise understanding [56]. Additionally, the second onset after a $15 \mathrm{~ms}$ gap in the stimulus did not elicit a gamma activity, which is different from the P1. It further supported that the P1 and gamma responses are independent of each other $[57,58]$.

\subsection{N1 Responses}

The N1 response was significantly more prominent in the right auditory cortex than the left, even though the stimuli were presented binaurally. Right hemispheric dominance for responses to simple auditory stimuli has been reported before [59-61]. The anatomical difference between left and right auditory cortices seems to contribute to the hemispheric asymmetry. A simulation study suggested that the larger left-hemispheric auditory cortex extends over multiple folded areas such that external electromagnetic fields could partly 
cancel each other. Therefore the right auditory source amplitudes may be up to $50 \%$ larger than in the left hemisphere [62].

In comparison to the generally larger N1 in the right hemisphere, the various noise conditions affected the N1 symmetrically. Specifically, the N1 increase with binaural noise was of the same order of magnitude from the left and right hemispheres. However, the earlier P1 and gamma responses showed asymmetries with monaural stimulation. These findings of different effects of noise on the N1 and the P1 suggest that these two responses index different aspects of auditory processing in agreement with previous studies $[63,64]$.

The N1 amplitude was not attenuated by concurrent noise, although the SNR was strongly reduced, especially when presenting the high-level noise. In contrast, noise affected the earlier evoked responses. Therefore, we assume that a control mechanism exists that compensates for the loss in the SNR.

The finding that low binaural noise increased the N1 amplitude agrees with EEG studies [13-15] and previous MEG studies from our group [10-12], and this noise-induced enhancement could be related to efferent feedback connections between the auditory cortex and the thalamus, inferior colliculus, and auditory brainstem nuclei. Such efferent feedback would enhance the SNR in adverse listening situations. The present study showed that the noise-related increase in N1 occurs only with binaural noise. In contrast, monaural noise of the same intensity did not affect the N1 amplitude, consistent with EEG findings [14]. However, the effects of efferent feedback have been explicitly shown as improvements in detecting complex sounds in the presence of contralateral noise that resulted in the release from ipsilateral masking [16]. The new finding that only binaural noise enhanced the N1 amplitude seems consistent with efferent feedback connections to lower auditory centers. However, if the olivocochlear efferent is the reason for the N1 increase, it should first cause a similar effect on P1 amplitude. Since there was no noise-induced enhancement in the P1 amplitude, the efferent feedback is unlikely to be the reason for the noise-related increase in N1.

An alternative account is that the increased N1 amplitude may be a consequence of the effects of binaural noise on the earlier evoked P1 responses. P1 was substantially attenuated bilaterally with high-level binaural noise, while the N1 amplitude was not different from the no-noise condition. A smaller P1 amplitude could indicate reduced sensory gating, resulting in unreduced N1 amplitudes even though the concurrent noise impaired the afferent inputs bilaterally.

The findings that high-level binaural noise substantially attenuated the P1 but did not affect N1 can be viewed as an effect of reduced sensory gating in the case of noise. Sensory gating at an early stage of processing, as reflected by stronger P1 suppression, increased the SNR at the subsequent stage, allowing for clear detection of the target stimulus [63]. Such a control mechanism may be necessary for preserving the N1 amplitude under the high binaural noise condition. The increase in the N1 amplitude in the low binaural noise condition could have been caused by an 'over-initiation' of downregulating the sensorygating mechanism at the earlier stage, which could explain the bell-shaped N1 amplitude characteristics as a function of the noise level.

The N1 amplitude was not affected by monaural noise and did not show an amplitude increase with low-level noise. One speculation is that in the case of left ear noise, the stimulus in the right ear was projected undisturbed along the afferent pathways and resulted in an unambiguous representation at the cortical level. Thus, no or less modulation of sensory gain was required for compensating a loss in the SNR. No N1 overshoot occurred because of the lesser effect of gain control. More research is necessary to understand the effects of peripheral and central interferences on sensory-gating mechanisms.

Energetic masking was used in the present study. Prior research revealed that masking with babble noise reduced N1 amplitude more than white noise $[65,66]$. One reason for the noise-induced N1 increase might be related to the weaker masking caused by the white noise, resulting in an 'over-initiation' at the sensory-gating stage. Namely, the human auditory system overestimates the masking effect caused by the low binaural white 
noise. Accordingly, when noise only comes from one ear, the auditory system would not overestimate its impact.

Similar to the N1 amplitude elicited by the onset of stimuli, the N1 amplitude for the gap response was also larger in the low binaural noise condition than in other conditions. This means that the system can 'over-initiate' the sensory modulation mechanism more than once in a short-term period. Namely, low-level background noise could facilitate temporal segmentation of auditory events, facilitating sound object organization.

\subsection{P2 Responses}

P2 has been proposed to represent some aspects of higher-order perceptual processing [67-69]. The effects of noise on the P2 amplitude were mainly observed in the right hemisphere, with P2 amplitudes smaller in both binaural noise conditions than in the monaural and no-noise conditions. Only the amplitude in low binaural noise was smaller in the left hemisphere than in the low monaural condition. The gap P2 response amplitude was also smaller in the binaural than in monaural conditions for both hemispheres. This meant that, as the onset P2, the P2 amplitude elicited by the trailing gap marker was more reduced by the binaural noise than by the monaural noise.

Ross, Miyazaki, and Fujioka [19] showed that the central masking did reduce the P2 amplitude in the right hemisphere for right ear stimulation and contralateral noise. They proposed that the central masking affected auditory processing at the level of auditory object representation. In the present study, binaural noise reduced the P2 amplitude in both hemispheres more strongly than the monaural noise. However, the difference in the right hemisphere was more evident than in the left hemisphere. Besides the 'central masking' from the contralateral side, the ipsilateral noise also caused a 'peripheral masking' by interactions at the cochlea $[19,70]$. For binaural noise, the masking could be from both contralateral and ipsilateral sides. However, for the monaural noise to the left ear, the masking was mainly from one side (ipsilateral side for the left ear, or contralateral side for the right ear). Thus, the P2 amplitude was smaller in the binaural than in monaural noise conditions. Ipsilateral masking might also be more dominant since the difference in P2 amplitude between binaural and monaural noise conditions was larger in the right than in the left hemisphere.

Furthermore, the increase of N1 in the low binaural condition did not extend to the P2 amplitude. It appeared that there was no direct relationship between the increase of N1 and the results of $\mathrm{P} 2$ amplitude. This is consistent with our proposal that the noise-related increase in N1 amplitude reflects the outcome of an 'over-initiation' mechanism, and it did not change the perceptual processing.

\section{Concluding Remarks}

The P1 amplitude and gamma synchronization were both reduced with the increase of noise intensity. This means that the sensory modulation was initiated to suppress the noise at the early stage. The low binaural noise generated larger N1 amplitude, but other types of noise did not have the same effect as the low binaural noise did. Our findings extend those of earlier studies by showing that a noise-related increase in $\mathrm{N} 1$ amplitude takes place only under binaural noise conditions. This situation could cause 'over-initiation' of the inhibition mechanism at the earlier stage and result in a stronger involuntary switch of attention to the stimulus at a subsequent stage, and larger N1 amplitude was apparent. Of course, there might be other mechanisms under this phenomenon, and more research in this area needs to be carried out in the future.

Author Contributions: This study was designed by C.A. and B.R. The data were collected and analyzed by D.S. All three authors contributed to the interpretation of the findings and writing of the manuscript. All authors have read and agreed to the published version of the manuscript. 
Funding: This research was supported by a grant from the Natural Sciences and Engineering Research Council of Canada (RGPIN-2016-05523) to CA and the Canadian Institute of Health Research to BR (Grant number MOP125925).

Institutional Review Board Statement: The study protocol was approved by the research ethics board at Baycrest Centre (REB \# 06-31).

Informed Consent Statement: All participants provided written consent after being informed about the study.

Data Availability Statement: Data can be made available upon request and approval through the research ethics board.

Conflicts of Interest: The authors declare no competing financial interest.

\section{References}

1. Davis, H.; Morgan, C.T.; Hawkins, J.E.; Galambos, R.; Smith, F.W. Temporary deafness following exposure to loud tones and noise. Laryngoscope 1946, 56, 19-21. [CrossRef]

2. Phillips, D.P. Temporal response features of cat auditory cortex neurons contributing to sensitivity to tones delivered in the presence of continuous noise. Hear. Res. 1985, 19, 253-268. [CrossRef]

3. Phillips, D.P. Neural representation of sound amplitude in the auditory cortex: Effects of noise masking. Behav. Brain Res. 1990, 37, 197-214. [CrossRef]

4. Billings, C.J.; Tremblay, K.L.; Stecker, G.C.; Tolin, W.M. Human evoked cortical activity to signal-to-noise ratio and absolute signal level. Hear. Res. 2009, 254, 15-24. [CrossRef]

5. Kaplan-Neeman, R.; Kishon-Rabin, L.; Henkin, Y.; Muchnik, C. Identification of syllables in noise: Electrophysiological and behavioral correlates. J. Acoust. Soc. Am. 2006, 120, 926-933. [CrossRef]

6. Whiting, K.A.; Martin, B.A.; Stapells, D.R. The effects of broadband noise masking on cortical event-related potentials to speech sounds /ba/ and /da. Ear Hear. 1998, 19, 218-231. [CrossRef]

7. Zeng, F.G.; Fu, Q.J.; Morse, R. Human hearing enhanced by noise. Brain Res. 2000, 869, 251-255. [CrossRef]

8. Näätänen, R.; Picton, T. The n1 wave of the human electric and magnetic response to sound: A review and an analysis of the component structure. Psychophysiology 1987, 24, 375-425. [CrossRef] [PubMed]

9. Koerner, T.K.; Zhang, Y. Effects of background noise on inter-trial phase coherence and auditory n1-p2 responses to speech stimuli. Hear. Res. 2015, 328, 113-119. [CrossRef]

10. Alain, C.; McDonald, K.; Van Roon, P. Effects of age and background noise on processing a mistuned harmonic in an otherwise periodic complex sound. Hear. Res. 2012, 283, 126-135. [CrossRef]

11. Alain, C.; Quan, J.; McDonald, K.; Van Roon, P. Noise-induced increase in human auditory evoked neuromagnetic fields. Eur. J. Neurosci. 2009, 30, 132-142. [CrossRef] [PubMed]

12. Alain, C.; Roye, A.; Salloum, C. Effects of age-related hearing loss and background noise on neuromagnetic activity from auditory cortex. Front. Syst. Neurosci. 2014, 8, 8. [CrossRef]

13. Billings, C.J.; Gordon, S.Y.; McMillan, G.P.; Gallun, F.J.; Molis, M.R.; Konrad-Martin, D. Noise-induced enhancement of envelope following responses in normal-hearing adults. J. Acoust. Soc. Am. 2020, 147, EL201. [CrossRef]

14. Papesh, M.A.; Billings, C.J.; Baltzell, L.S. Background noise can enhance cortical auditory evoked potentials under certain conditions. Clin. Neurophysiol. 2015, 126, 1319-1330. [CrossRef] [PubMed]

15. Parbery-Clark, A.; Marmel, F.; Bair, J.; Kraus, N. What subcortical-cortical relationships tell us about processing speech in noise. Eur. J. Neurosci. 2011, 33, 549-557. [CrossRef] [PubMed]

16. Giraud, A.L.; Garnier, S.; Micheyl, C.; Lina, G.; Chays, A.; Chéry-Croze, S. Auditory efferents involved in speech-in-noise intelligibility. NeuroReport 1997, 8, 1779-1783. [CrossRef] [PubMed]

17. Lopez-Poveda, E.A. Olivocochlear efferents in animals and humans: From anatomy to clinical relevance. Front. Neurol. 2018, 9 , 197. [CrossRef]

18. Okamoto, H.; Stracke, H.; Ross, B.; Kakigi, R.; Pantev, C. Left hemispheric dominance during auditory processing in a noisy environment. BMC Biol. 2007, 5, 52. [CrossRef]

19. Ross, B.; Miyazaki, T.; Fujioka, T. Interference in dichotic listening: The effect of contralateral noise on oscillatory brain networks. Eur. J. Neurosci. 2012, 35, 106-118. [CrossRef]

20. Adler, L.E.; Olincy, A.; Waldo, M.; Harris, J.G.; Griffith, J.; Stevens, K.; Flach, K.; Nagamoto, H.; Bickford, P.; Leonard, S.; et al. Schizophrenia, sensory gating, and nicotinic receptors. Schizophr. Bull. 1998, 24, 189-202. [CrossRef]

21. Freedman, R.; Adler, L.E.; Gerhardt, G.A.; Waldo, M.; Baker, N.; Rose, G.M.; Drebing, C.; Nagamoto, H.; Bickford-Wimer, P.; Franks, R. Neurobiological studies of sensory gating in schizophrenia. Schizophr. Bull. 1987, 13, 669-678. [CrossRef]

22. Freedman, R.; Adler, L.E.; Myles-Worsley, M.; Nagamoto, H.T.; Miller, C.; Kisley, M.; McRae, K.; Cawthra, E.; Waldo, M. Inhibitory gating of an evoked response to repeated auditory stimuli in schizophrenic and normal subjects. Human recordings, computer simulation, and an animal model. Arch. Gen. Psychiatry 1996, 53, 1114-1121. [CrossRef] 
23. Boutros, N.N.; Korzyukov, O.; Jansen, B.; Feingold, A.; Bell, M. Sensory gating deficits during the mid-latency phase of information processing in medicated schizophrenia patients. Psychiatry Res. 2004, 126, 203-215. [CrossRef] [PubMed]

24. Jerger, K.; Biggins, C.; Fein, G. P50 suppression is not affected by attentional manipulations. Biol. Psychiatry 1992, 31, 365-377. [CrossRef]

25. Wan, L.; Friedman, B.H.; Boutros, N.N.; Crawford, H.J. P50 sensory gating and attentional performance. Int J. Psychophysiol. 2008, 67, 91-100. [CrossRef] [PubMed]

26. Freedman, R.; Waldo, M.; Bickford-Wimer, P.; Nagamoto, H. Elementary neuronal dysfunctions in schizophrenia. Schizophr. Res. 1991, 4, 233-243. [CrossRef]

27. Hall, J.W., 3rd; Grose, J.H. The relation between gap detection, loudness, and loudness growth in noise-masked normal-hearing listeners. J. Acoust. Soc. Am. 1997, 101, 1044-1049. [CrossRef]

28. Shailer, M.J.; Moore, B.C. Detection of temporal gaps in bandlimited noise: Effects of variations in bandwidth and signal-to-masker ratio. J. Acoust. Soc. Am. 1985, 77, 635-639. [CrossRef]

29. Ross, B.; Schneider, B.; Snyder, J.S.; Alain, C. Biological markers of auditory gap detection in young, middle-aged, and older adults. PLoS ONE 2010, 5, e10101. [CrossRef]

30. Clementz, B.A.; Blumenfeld, L.D.; Cobb, S. The gamma band response may account for poor p50 suppression in schizophrenia. NeuroReport 1997, 8, 3889-3893. [CrossRef]

31. Kisley, M.A.; Cornwell, Z.M. Gamma and beta neural activity evoked during a sensory gating paradigm: Effects of auditory, somatosensory and cross-modal stimulation. Clin. Neurophysiol. 2006, 117, 2549-2563. [CrossRef] [PubMed]

32. Müller, M.M.; Keil, A.; Kissler, J.; Gruber, T. Suppression of the auditory middle-latency response and evoked gamma-band response in a paired-click paradigm. Exp. Brain Res. 2001, 136, 474-479. [CrossRef]

33. Tadel, F.; Baillet, S.; Mosher, J.C.; Pantazis, D.; Leahy, R.M. Brainstorm: A user-friendly application for meg/eeg analysis. Comput. Intell. Neurosci. 2011, 2011, 879716. [CrossRef] [PubMed]

34. Jung, T.P.; Makeig, S.; Humphries, C.; Lee, T.W.; McKeown, M.J.; Iragui, V.; Sejnowski, T.J. Removing electroencephalographic artifacts by blind source separation. Psychophysiology 2000, 37, 163-178. [CrossRef]

35. Dale, A.M.; Liu, A.K.; Fischl, B.R.; Buckner, R.L.; Belliveau, J.W.; Lewine, J.D.; Halgren, E. Dynamic statistical parametric mapping: Combining fmri and meg for high-resolution imaging of cortical activity. Neuron 2000, 26, 55-67. [CrossRef]

36. Tadel, F.; Bock, E.; Niso, G.; Mosher, J.C.; Cousineau, M.; Pantazis, D.; Leahy, R.M.; Baillet, S. Meg/eeg group analysis with brainstorm. Front. Neurosci. 2019, 13, 76. [CrossRef]

37. Cohen, M.X. A better way to define and describe morlet wavelets for time-frequency analysis. NeuroImage 2019, 199, 81-86. [CrossRef]

38. Pfurtscheller, G.; Aranibar, A. Evaluation of event-related desynchronization (erd) preceding and following voluntary self-paced movement. Electroencephalogr. Clin. Neurophysiol. 1979, 46, 138-146. [CrossRef]

39. Pfurtscheller, G.; Lopes da Silva, F.H. Event-related eeg/meg synchronization and desynchronization: Basic principles. Clin. Neurophysiol. 1999, 110, 1842-1857. [CrossRef]

40. Pantev, C.; Makeig, S.; Hoke, M.; Galambos, R.; Hampson, S.; Gallen, C. Human auditory evoked gamma-band magnetic fields. Proc. Natl. Acad. Sci. USA 1991, 88, 8996-9000. [CrossRef]

41. White, P.M.; Yee, C.M. P50 sensitivity to physical and psychological state influences. Psychophysiology 2006, 43, 320-328. [CrossRef]

42. Bruyns-Haylett, M.; Luo, J.; Kennerley, A.J.; Harris, S.; Boorman, L.; Milne, E.; Vautrelle, N.; Hayashi, Y.; Whalley, B.J.; Jones, M.; et al. The neurogenesis of p1 and n1: A concurrent eeg/lfp study. NeuroImage 2017, 146, 575-588. [CrossRef]

43. Korzyukov, O.; Pflieger, M.E.; Wagner, M.; Bowyer, S.M.; Rosburg, T.; Sundaresan, K.; Elger, C.E.; Boutros, N.N. Generators of the intracranial p50 response in auditory sensory gating. NeuroImage 2007, 35, 814-826. [CrossRef] [PubMed]

44. Huang, M.X.; Edgar, J.C.; Thoma, R.J.; Hanlon, F.M.; Moses, S.N.; Lee, R.R.; Paulson, K.M.; Weisend, M.P.; Irwin, J.G.; Bustillo, J.R.; et al. Predicting eeg responses using meg sources in superior temporal gyrus reveals source asynchrony in patients with schizophrenia. Clin. Neurophysiol. 2003, 114, 835-850. [CrossRef]

45. Reite, M.; Teale, P.; Zimmerman, J.; Davis, K.; Whalen, J. Source location of a 50 msec latency auditory evoked field component. Electroencephalogr. Clin. Neurophysiol. 1988, 70, 490-498. [CrossRef]

46. Woods, D.L.; Alain, C.; Covarrubias, D.; Zaidel, O. Frequency-related differences in the speed of human auditory processing. Hear. Res. 1993, 66, 46-52. [CrossRef]

47. Ninomiya, H.; Sato, E.; Onitsuka, T.; Hayashida, T.; Tashiro, N. Auditory p50 obtained with a repetitive stimulus paradigm shows suppression to high-intensity tones. Psychiatry Clin. Neurosci. 2000, 54, 493-497. [CrossRef]

48. Weate, S.J.; Moore, J.L.; Drake, M.E., Jr. Effect of frontal and temporal seizure foci on p50 auditory evoked potentials. Clin. Electroencephalogr. 1995, 26, 214-218. [CrossRef] [PubMed]

49. Adler, L.E.; Hoffer, L.; Nagamoto, H.T.; Waldo, M.C.; Kisley, M.A.; Giffith, J.M. Yohimbine impairs p50 auditory sensory gating in normal subjects. Neuropsychopharmacology 1994, 10, 249-257. [CrossRef]

50. Herrmann, C.S.; Munk, M.H.; Engel, A.K. Cognitive functions of gamma-band activity: Memory match and utilization. Trends Cogn. Sci 2004, 8, 347-355. [CrossRef]

51. Bertrand, O.; Tallon-Baudry, C. Oscillatory gamma activity in humans: A possible role for object representation. Int. J. Psychophysiol. 2000, 38, 211-223. [CrossRef] 
52. Elliott, M.A.; Muller, H.J. Evidence for 40-hz oscillatory short-term visual memory revealed by human reaction-time measurements. J. Exp. Psychol. Learn. Mem. Cogn. 2000, 26, 703-718. [CrossRef]

53. Ross, B.; Fujioka, T. 40-hz oscillations underlying perceptual binding in young and older adults. Psychophysiology 2016, 53, 974-990. [CrossRef] [PubMed]

54. Ross, B.; Herdman, A.T.; Pantev, C. Stimulus induced desynchronization of human auditory 40-hz steady-state responses. J. Neurophysiol. 2005, 94, 4082-4093. [CrossRef]

55. Tallon-Baudry, C.; Bertrand, O. Oscillatory gamma activity in humans and its role in object representation. Trends Cogn. Sci. 1999, 3, 151-162. [CrossRef]

56. Ross, B.; Dobri, S.; Schumann, A. Speech-in-noise understanding in older age: The role of inhibitory cortical responses. Eur. J. Neurosci. 2019, 51, 891-908. [CrossRef]

57. Narici, L.; Carozzo, S.; Lopez, L.; Ogliastro, C.; Sannita, W.G. Phase-locked oscillatory approximately 15- to 30-hz response to transient visual contrast stimulation: Neuromagnetic evidence for cortical origin in humans. Neuroimage 2003, 19, 950-958. [CrossRef]

58. Sannita, W.G.; Lopez, L.; Piras, C.; Di Bon, G. Scalp-recorded oscillatory potentials evoked by transient pattern-reversal visual stimulation in man. Electroencephalogr. Clin. Neurophysiol. 1995, 96, 206-218. [CrossRef]

59. Howard, M.F.; Poeppel, D. Hemispheric asymmetry in mid and long latency neuromagnetic responses to single clicks. Hear. Res. 2009, 257, 41-52. [CrossRef] [PubMed]

60. Ross, B.; Herdman, A.T.; Pantev, C. Right hemispheric laterality of human $40 \mathrm{hz}$ auditory steady-state responses. Cereb. Cortex 2005, 15, 2029-2039. [CrossRef]

61. Kanno, A.; Nakasato, N.; Fujiwara, S.; Yoshimoto, T. Right hemispheric dominancy in the auditory evoked magnetic fields for pure-tone stimuli. Brain Nerve 1996, 48, x1-x243.

62. Shaw, M.E.; Hämäläinen, M.S.; Gutschalk, A. How anatomical asymmetry of human auditory cortex can lead to a rightward bias in auditory evoked fields. NeuroImage 2013, 74, 22-29. [CrossRef] [PubMed]

63. Kisley, M.A.; Noecker, T.L.; Guinther, P.M. Comparison of sensory gating to mismatch negativity and self-reported perceptual phenomena in healthy adults. Psychophysiology 2004, 41, 604-612. [CrossRef]

64. Boutros, N.N.; Belger, A. Midlatency evoked potentials attenuation and augmentation reflect different aspects of sensory gating. Biol. Psychiatry 1999, 45, 917-922. [CrossRef]

65. Billings, C.J.; Bennett, K.O.; Molis, M.R.; Leek, M.R. Cortical encoding of signals in noise: Effects of stimulus type and recording paradigm. Ear Hear. 2011, 32, 53-60. [CrossRef] [PubMed]

66. Ross, B. Auditory cortex responses to interaural time differences in the envelope of low-frequency sound, recorded with meg in young and older listeners. Hear. Res. 2018, 370, 22-39. [CrossRef]

67. Luck, S.J.; Hillyard, S.A. Electrophysiological correlates of feature analysis during visual search. Psychophysiology 1994, 31, 291-308. [CrossRef]

68. Alain, C.; Roye, A.; Arnott, S.A. Middle and late auditory evoked responses: What are they telling us on central auditory disorders. In Disorders of Peripheral and Central Auditory Processing: Handbook of Clinical Neurophysiology; Celesia, G.G., Ed.; Elsevier: Amsterdam, The Netherlands, 2013; Volume 10, pp. 177-199.

69. Alain, C.; Ross, B. The role of neuroelectric and neuromagnetic recordings in assessing learning and rehabilitation effects. In Cognitive Neurorehabilitation, Evidence and Applications, 2nd ed.; Stuss, D.T., Winocur, G., Eds.; Cambridge University Press: New York, NY, USA, 2008; pp. 183-199.

70. Wegel, R.L.; Lane, C.E. Auditory masking of one pure tone by another. Phys. Rev. 1924, 23, 266-285. [CrossRef] 